\title{
A Estrutura da Brincadeira e a Regulação das Relações
}

\author{
Fernando Augusto Ramos Pontes ${ }^{1}$ e Celina Maria Colino Magalhães \\ Universidade Federal do Pará
}

\begin{abstract}
RESUMO: A brincadeira tradicional de rua é um fenômeno paradigmático da organização social de crianças e da cultura infantil. O estudo das brincadeiras tradicionais infantis possibilita a investigação de um fenômeno "espontâneo", sem o planejamento adulto e sem o recurso da escrita. Cada brincadeira, em cada cultura, possui uma estrutura peculiar que a define. A estrutura da brincadeira, no geral determina o desenrolar dos acontecimentos no jogo, prevendo padrões, estratégias e sanções típicas. Apesar desta estrutura ter sua origem histórica nas relações, constitui um elemento supra-relacional, ritualizado. Cada característica estrutural, verbalmente codificada, existe independente das relações, é um dos seus determinantes. Na verdade, a estrutura de uma brincadeira não determina totalmente e linearmente as interações entre os sujeitos de modo a eliminar as peculiaridades das relações; a estrutura interage com as relações anteriormente dadas. As interações nas brincadeiras serão fruto do institucionalmente dado e das relações entre seus membros. A partir de exemplos de brincadeiras tradicionais tais como, peteca (bola de gude), papagaio, tratos, elástico e outras, serão analisados aspectos estruturais que condicionam e interagem com as relações. Acredita-se que a investigação de tais fatores seja importante tanto para melhor descrição da brincadeira quanto para compreensão das relações entre os membros do grupo bem como da transmissão da cultura da brincadeira.
\end{abstract}

Palavras-chave: estrutura da brincadeira; jogos; interação entre crianças; transmissão cultural.

\section{The Structure of Play and the Regulation of Relationships}

\begin{abstract}
Traditionally, street play has played an important role in structuring child social organization and culture. This study of child play focuses on play as a spontaneous phenomenon which occurs without adult guidance and written rules. In all cultures each play activity has a particular structure which defines it. In general, this structure leads to the development of particular game patterns, strategies, and sanctions. Although this structure arose from child interactions, it constitutes a ritualized "supra-relationship"; that is, although each verbally-coded structural characteristic may exist independently from constraints placed on it, the same may act as a determinant in some situations. In practice, play structure does not affect child interactions, in the sense of eliminating particular types of interpersonal relations that were previously established. Beginning with traditional games such as marbles, kiting, and tag, those structural aspects that condition, or interact with interpersonal relations were studied. It is believed that a thorough investigation of these factors is necessary in order to better describe the nature of games and comprehend how within-group relations influence the transmission of play culture.
\end{abstract}

Key words: play structure; games; child interaction; cultural transmission.

Este artigo tem como ponto de partida a seguinte tese: a estrutura de uma brincadeira - enquanto um elemento emergente das relações (ritualizado) - é um dos determinantes das relações infantis no sentido de possibilitar arranjos sociais. Entretanto tal determinação não se impõe à relação, ela se ajusta. As interações em uma brincadeira serão fruto do arranjo entre o institucional e o relacionalmente dado. Pretende-se neste artigo problematizar e discutir questões pertinentes a esta tese.

A brincadeira de rua é, em nosso entender, um fenômeno paradigmático para o estudo da organização social de crianças e da cultura infantil. $\mathrm{O}$ estudo de brincadeiras tradicionais possibilita a investigação de um fenômeno "espontâneo" infantil, sem o planejamento adulto e sem o recurso da escrita. Como assinalaram Opie e Opie (1976:40), "Nos jogos tradicionais de rua as crianças se engajam em regras testadas por séculos, que são passadas de criança para crian-

1 Endereço: Av. Rodrigues de Farias N. ${ }^{\circ} 16$ - Curió - CEP:66095-240 E-mail: farp@cpgp.ufpa.br ça sem nenhuma referência a escrita, parlamento ou a alguma propriedade adulta". Mesmo em situações precárias de sobrevivência as crianças na rua não se apresentam como desprivilegiadas, ou carentes; antes, mostram-se como seres humanos exercendo as capacidades humanas de apropriação e transmissão de práticas culturais.

Jogos tradicionais infantis caracterizam uma cultura local (Friedmann, 1990). É interessante observar a existência de certos padrões lúdicos universais, mesmo com diferenças regionais, variações na designação ou na existência ou supressão de certas regras.

A brincadeira de "cabra-cega", já era cultivada entre os romanos no século III a.C. com o nome de murinda; na Espanha tem o nome de "galinha-cega"; na Alemanha, de "vaca-cega"; nos Estados Unidos, de "Blindman's buff; na França, de "Colinmaillard" (Medeiros, 1990); em Campinas (São Paulo) é "cobra-cega" (Tavares, 1994); em Ponta de Pedras (município situado na ilha do Marajó - Pará) tem o nome de "pata-cega". Em todas estas localidades a estrutura da brincadeira é extremamente semelhante. A peteca que possibilita jogar "o jogo de peteca" em Belém, no mun- 
do inglês é conhecida como "game of marble", "bille" na França, "bola de gude" no Rio de Janeiro e no Espírito Santo, "baleba" no norte fluminense, "bola de búrica" no Paraná, "bolinha de vidro" entre a população luso-açoriana do litoral catarinense, "clica" (talvez aportuguesamento do alemão "Klicker" - bola) nas áreas catarinenses de colonização alemã, "bulinha" nos arredores de Belo Horizonte, "chimbre" em Alagoas (Neto, 1977). Conservação, mudança e universalidade são palavras-chave para a compreensão destes jogos (Kishimoto, 1993).

Pouco se sabe sobre a real origem de diversos jogos, entretanto, sua transmissão de criança para criança se dá de forma essencialmente oral.

No sentido sociológico do termo, pode-se dizer que as brincadeiras tradicionais infantis configuram-se como verdadeiras instituições pois são estruturas decorrentes de necessidades sociais básicas, com caráter de relativa permanência e identificáveis pelo valor de seus códigos de conduta.

A estrutura de uma brincadeira, remete-nos a problemas de ordem classificatória essenciais para os delineamentos de futuras pesquisas (Avedon \& Sutton-Smith, 1971). Dentre os trabalhos encontrados na literatura enfocando aspectos estruturais dos jogos encontra-se o de o Redl, Gump e Sutton-Smith (1971) e o de Avedon (1971).

Redl e colaboradores (1971) procuram delinear algumas dimensões que permitem analisar o quanto o jogo é adequado para as necessidades ou capacidades da criança, dentre estas estão: o contato corporal,. A atividade corporal, as habilidades requeridas, os fatores da competição, o uso do espaço, etc.

Avedon (1971), combinando o trabalho de matemáticos e estudiosos do comportamento, identificou nove elementos estruturais no jogos: 1) propósito ou razão, 2) procedimentos de ação, 3) regras que governam a ação 4) número de jogadores requeridos, 5) papéis dos participantes, 6) habilidades e qualificação requerida, 7) padrões de interações dos participantes, 8) cenário físico e ambiente requerido e 9) equipamento requerido.

A despeito das várias dimensões (Redl \& e col., 1971) e de elementos estruturais (Avedon, op. cit.), foge ao interesse deste trabalho o detalhamento de tais aspectos. Para os nossos objetivos define-se estrutura da brincadeira como elementos gerais que permitem perceber uma determinada ordem ou organização da brincadeira em questão, de modo que se possa identificar relações entre outras brincadeiras de natureza semelhante, e assim, perceber as caracteristicas ou a funções ou funcionamento do todo.

Devemos, entretanto, nos acautelar em relação às perigosas e complexas implicações do conceito de estrutura. Em primeiro lugar, este termo pode ter implicações estáticas que são bastante errôneas quando aplicadas a fenômenos sociais, principalmente no caso aqui explanado. Formas de brincar que caracterizam determinada estrutura de uma brincadeira modificam-se no tempo e no espaço e, como salienta a tese principal deste trabalho, modificam-se em função da rede de relações especificadas dentro de um grupo. Em segundo lugar, deve sempre estar claro que a estrutura não é uma realidade empírica, não é imediatamente visível na realidade; ela é abstraída e imposta pelo observador.

\section{Os Jogos e as Regras de uma Brincadeira}

A estrutura de uma brincadeira pode ser identificada de uma forma mais conspícua através de suas regras. Apesar de bastante controverso (Bomtempo, Hussein e Zamberlan, 1986), brincadeiras com regras são identificadas como jogos (Aurélio, 2000).

Os jogos são uma forma tipicamente humana de brincar envolvendo a ritualização de papéis e a regulação de determinados cenários. Nos jogos as seqüências imprevisíveis características das brincadeiras são transformadas em um ciclo repetitivo e ritualizado de ação com início, meio e fim. Em conjunção com este processo, a alternação informal de papéis característica da brincadeira é transformada em uma alternação regularizada entre competidores e grupos. Jogos diferem de outras formas de brincar por requererem que ao menos um dos jogadores tenha a concepção do cenário, das regras, de suas sanções, e que o outro jogador tenha a habilidade cognitiva para seguir as regras (Parker, 1986).

As regras do jogo têm por fim regular os comportamentos dos brincantes limitando suas possibilidades de ação e/ ou determinando estratégias possíveis de desenvolvimento e do desenrolar da brincadeira.

Diferentemente de uma legislação jurídica, as regras nos jogos tradicionais de rua foram geradas de forma totalmente assistemática, sem nenhum planejamento central; a coerência e a ausência de contradições ou a dubiedade de elementos foram estruturados e desenvolvidos nas interações entre crianças no decorrer de várias gerações. Deste modo a estrutura é construída a partir de critérios desenvolvidos pelo observador; é ele que busca a organização lógica interna da brincadeira.

Acredita-se que a compreensão desta estrutura de regras seja útil não somente para uma melhor descrição da brincadeira em si, como também para compreensão da regulação dos membros do grupo e de como eles se comportam com relação a esta regulação.

\section{A peteca: da inflexibilidade à flexibilidade na observância das}

Pontes e Galvão (1992) desenvolveram categorias funcionais para permitir uma visão das regras no jogo de peteca de maneira integrada e o estudo sistemático do desenvolvimento do uso da regra no jogo pela criança (ver figura 1). Eles propuseram uma divisão das regras do jogo de peteca nas seguintes categorias abrangentes para organizar o estudo da aprendizagem das habilidades envolvidas no jogo: Regras preliminares gerais (RPG), Regras preliminares da modalidade (RPM), Regras das modalidades (RM), Regras variantes das modalidades (VM) e Regras Circunstanciais (RC) (ver Figura 1).

Correspondem às RPG os comportamentos padronizados comuns às modalidades pesquisadas como: "jogar do 


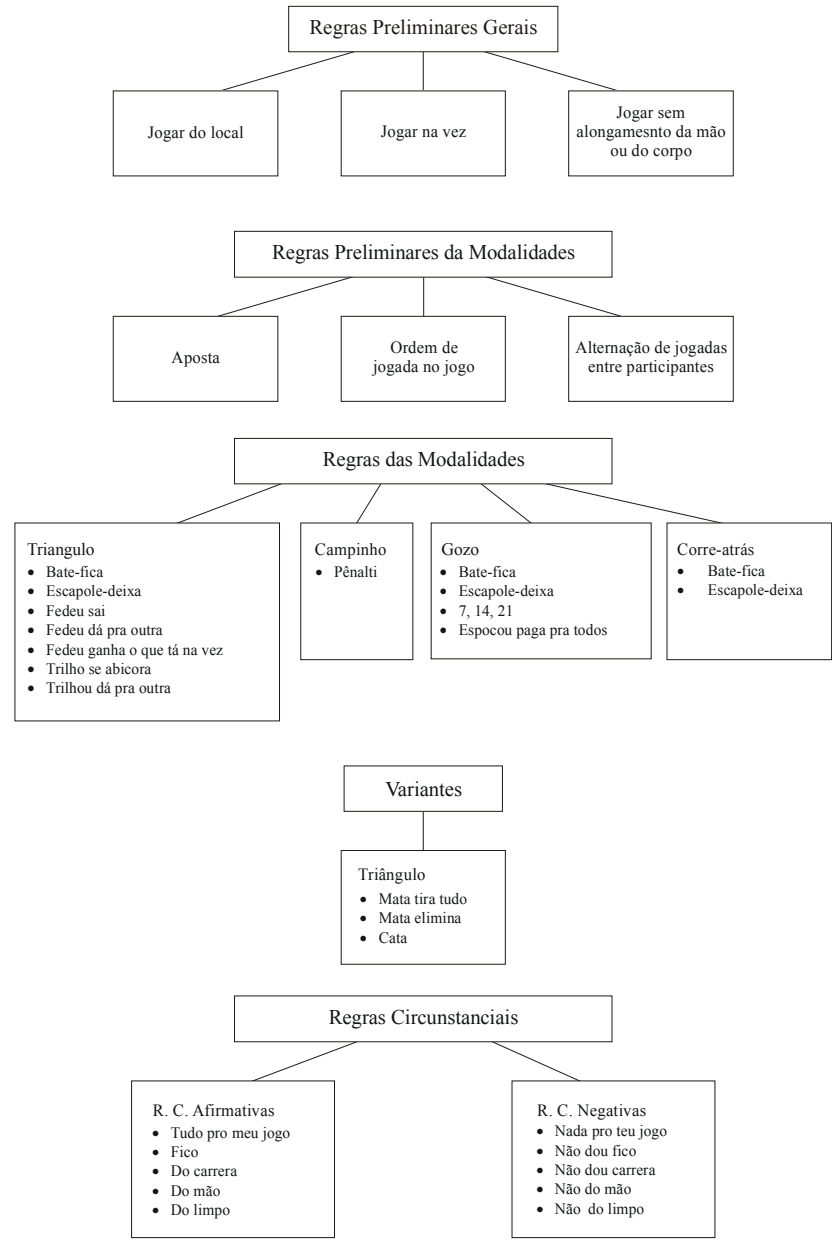

Figura 1: Categorias funcionais das regras no jogo de peteca

local”, "jogar na vez”. Já as RPM referem-se aos comportamentos padronizados peculiares de cada modalidade, tais como: "aposta", "decisão da ordem de jogada". As RM são verbalmente codificadas e entram em vigência geralmente no início da partida; pertencem a esta categoria as regras como: "fedeu sai" e "bate fica". As VM apresentam características semelhantes às $\mathrm{RM}$ com relação à maneira com que entram em vigência e a duração desta; diferem desta, entretanto, pois a sua entrada em vigor determina a estratégia principal para vencer a partida. Por exemplo: na modalidade triângulo existe as variantes "mata tira tudo", "mata elimina" e "cata". Por fim, uma RC só entra em vigor através da verbalização de um dos participantes e tem vigência somente na jogada em que foi verbalizada; as RC dividem-se em afirmativas (RCA) e negativas (RCN). As RCA permitem certos comportamentos ao jogador que verbaliza, como por exemplo: “Tudo pro meu jogo.", "Dô mão.”, "Fico.”. As RCN proíbem a execução de certos comportamentos que seriam permitidos pelas RCA como: "Nada pro teu jogo.", "Não dô mão.", "Não dô fico.". Observações similares a essas foram feitas por Piaget (1977), sem a preocupação de formar um conjunto de categorias descritivas para o jogo de peteca.

Segundo Pontes e Galvão (1992), algumas regras são mais simples e essenciais para caracterizar a atividade como jogo, e outras são mais complexas e acessórias. É possível jogar peteca sem usar uma RC, mas seria impossível praticar o jogo sem usar as regras RPG, que envolvem comportamentos como o de jogar na vez, jogar do local onde se encontra a peteca, etc., ou as chamadas RPM, que definem a estrutura da modalidade do jogo (como começar, qual a conseqüência para cada situação, etc.).

Os desempenhos exigidos nas situações em que vigoram as RPG parecem evidenciar menor complexidade com relação aos exigidos pelas RC. Isto se deve, inclusive, ao fato da vigência da RPG ser indicada pelos companheiros para o jogador que eventualmente esteja agindo de forma não apropriada, enquanto que as regras circunstanciais vigoram apenas quando explicitadas no momento em que se configura ou está prestes a se configurar a situação. Com a verbalização de uma RC o jogador modifica as contingências em vigor, ou seja, as conseqüências para a jogada do adversário. Tal desempenho, em geral, implica em uma antecipação da situação de jogo na medida em que a regra circunstancial vigora apenas se verbalizada antes que o companheiro verbalize a sua contra-regra ou realize sua jogada.

Comportar-se de acordo com as regras do jogo implica necessariamente uma aprendizagem hierárquica, particularmente no que se refere à regra circunstancial com relação à regra preliminar geral, pois aprender a lidar com a primeira implica em aquisição de controle por parte de novas variáveis que negam ou colocam dentro de certa relatividade um conhecimento (controle) estabelecido anteriormente (regra do jogo). O jogo de peteca, mais do que um jogo de atirar (Friedman, 1996) é um jogo verbal com regras especificando padrões motores.

A partir de medidas simples, pode-se analisar o nível de desempenho dos sujeitos no jogo, o que permitiria conseqüentemente a descrição da evolução do jogar peteca, que pode ser definido como desenvolvimento da habilidade de usar as regras existentes no jogo em função das variáveis que se apresentam a cada momento (Pontes \& Galvão, 1987).

Dentre as variáveis passíveis de serem analisadas destacam-se: a) o número de erros cometidos por sujeito na situação de jogo, que seria o inverso do nível de desempenho de cada sujeito em seguir as regras do jogo; b) as correções para erros, que podem exemplificar a existência de conseqüência para comportamentos fora da regra e, também, indicar diferenças de competência entre jogadores; c) a freqüência de utilização de RC: como cada jogada é o momento na qual uma regra circunstancial pode ser verbalizada, a freqüência de utilização se constitui em indicador do desempenho, de cada sujeito, de aproveitar a oportunidade que cada jogada lhe provê d) a latência entre a situação estimuladora e verbalização de uma RC: a latência é essencial para a efetividade de tal RC; a diminuição do intervalo entre vez (momento de jogar) e verbalização de regra circunstancial, pode ser considerada mais um indicador da evolução do desempenho na prática do jogo.

A partir destes indicadores percebe-se que as formas de praticar ou de utilizar as regras são essencialmente diferentes em função do grupo de brincantes. Apesar da organiza- 
ção do grupo de jogo de peteca se dar em função de faixas etárias um tanto estreitas, percebe-se, em alguns momentos, sujeitos mais experientes partilhando o jogo com sujeitos mais novos. Em algumas situações os mais experientes são mais flexíveis para com os aprendizes; o rigor na aplicação das regras e no cumprimento das sanções parece ser bastante diferente do que o utilizado para sujeitos do mesmo nível, onde o jogo é altamente competitivo, o extrato abaixo é bastante ilustrativo desta questão:

Jogadores: Val (7 anos) e Len (8 anos).

Situação: Terreno levemente acidentado e está na vez de Val jogar.

Val: Verbaliza "Deixa, deixa ai!" e ao mesmo tempo passa a palma do pé alisando a terra (ação de compactar a terra).

Len: $\mathrm{O}$ que foi que tu disse?

Val: ééé........!

Len: Tudo!

Val erra por emitir um comportamento (compactar a terra) que só é permitido se uma RCA for antes verbalizada, por ex.: "tudo pro meu jogo" ou "tudo". Em função disto, Len poderia anular a ação de Val, ou falar "nada pro teu jogo" ou "nada".

Len é complacente com o erro de Val. É evidente que Val não faz deste modo por interesse em enganar e sim por inabilidade no uso da regra. Len interroga Val dando o indicativo de que para que tal ação fosse permitida, algo deveria ser verbalizado. Len é cúmplice com o processo de aprendizagem e com a transmissão de cultura. A competição parece estar por alguns momentos suspensa, a estrita observância à regra não é aplicada indiferentemente.

\section{O Trato: onde a lei é omissa cumpra-se o que se estabelece nas relações}

Os Tratos podem ser definidos como "acordos entre os brincantes que estabelecem que, quando determinados eventos do meio ocorrerem, alguns comportamentos devem ser emitidos. A não emissão do comportamento acordado implica em penalizações de caráter aversivo físico".

Para o trato entrar em vigor deve ser estabelecido o acordo recíproco entre díades (estes que espalham em redes pelo grupo). Para estabelecimento do acordo existem rituais típicos feitos com as mãos entre as partes interessadas.

$\mathrm{O}$ trato configura-se então como uma forma ritualizada de agressão. Os eventos disparadores dos tratos estende-se de estímulos presentes do meio físico a aspectos da aparência e do comportamento dos brincantes. Em períodos e grupos diferentes Pontes (1986) e Souza (1999) registraram, em Belém, vários tipos de tratos (ver quadro 1).

Para fins deste trabalho, interessa ressaltar que a partir dos tratos é possível montar uma rede de relações dentro do grupo. Sabe-se que alguns indivíduos são alvos preferenciais de tratos (os famosos sacos de pancada) enquanto que outros são sutilmente evitados. Por outro lado, sabe-se também que muitas vezes os tratos resultam em conflitos (Souza, 1999b). A origem dos conflitos na maioria de vezes não
Quadro 1: Descrição dos tratos encontrados por Pontes( 1986)* e Souza (1999)**.

\begin{tabular}{ll}
\hline $\begin{array}{c}\text { Denominação } \\
\text { do trato }\end{array}$ & \multicolumn{1}{c}{ Descrição } \\
\hline Mão no Bolso* & $\begin{array}{l}\text { Dar um tapa nas costas de quem não estiver com a } \\
\text { mão no bolso, bastando para isto, verbalizar antes de } \\
\text { dar o tapa a frase "mão no bolso". }\end{array}$ \\
\hline Avião* & $\begin{array}{l}\text { Sempre que passar um avião, as crianças com as quais } \\
\text { foi feito o acordo terão de cuspir, o último a cuspir ou } \\
\text { quem não cuspir levará bolo de todas as outras } \\
\text { crianças. }\end{array}$ \\
\hline Estátua* & $\begin{array}{l}\text { Ao se falar a palavra "estátua", a quem for } \\
\text { direcionado, terá que ficar imóvel. }\end{array}$ \\
\hline Coxinha** & $\begin{array}{l}\text { Levar um soco na coxa quando sentar sem pedir } \\
\text { licença. }\end{array}$ \\
\hline Mochila** & $\begin{array}{l}\text { Levar um soco nas costas quando sentar sem pedir } \\
\text { licença }\end{array}$ \\
\hline Verdura** & $\begin{array}{l}\text { Se falar palavrão pode levar um tapa em qualquer } \\
\text { lugar do corpo }\end{array}$ \\
\hline Bacuri** & $\begin{array}{l}\text { Se estiver distraído pode levar um tapa (geralmente na } \\
\text { cabeça) com as duas mãos espalmadas (antes as duas } \\
\text { mãos são assopradas) }\end{array}$ \\
\hline
\end{tabular}

reside no descumprimento da regra, mas sim, em discordâncias quanto à intensidade do golpe desferido.

A regra de um trato, quando comparada com outras brincadeiras mais complexas (peteca, elástico etc.), é bastante simples. Ela especifica somente que, na ocorrência de determinado evento determinados comportamentos (geralmente agressivos) são permitidos; ela não especifica a intensidade da emissão destes comportamentos ou para quem eles devem ser desferidos, é neste ponto que geralmente surgem os conflitos.

Tem-se então um claro exemplo de omissão da legislação, omissão que neste caso é preenchida pela "jurisprudência" das relações.

Entretanto, a análise da estrutura não se reduz à análise das regras da brincadeira. Como observado anteriormente este é somente o elemento mais conspícuo. Situar a brincadeira dentro de um contexto de outras brincadeiras e perceber a existência de elementos que possam facilitar a participação de sujeitos menos experientes, possibilitará identificar a existência de mecanismos para fins de transmissão da sua cultura. Refere-se aqui especificamente aos modos típicos de como a brincadeira é praticada.

\section{Brinquedos-Ponte, Brinquedos Aparentados e Formas Brandas}

O desenvolvimento de categorias que possibilitem a análise de como as brincadeiras se interarticulam e de estruturas internas que possam ser segregacionistas ou facilitadoras da participação de crianças menos experientes, são essenciais para compreensão da introdução da criança na cultura do brinquedo. Três categorias orientadoras iniciais foram por nós desenvolvidas: os brinquedos-ponte, os brinquedos apa- 
rentados e as formas brandas. Em cada um desses casos analisa-se a maneira como a brincadeira se encontra estruturada de modo que as habilidades exigidas possam ser desempenhadas de maneira gradual ou treinadas através de formas intermediárias.

\section{Os brinquedos-ponte: o brinquedo do brinquedo}

Denominam-se de brinquedos-ponte os brinquedos que replicam o brinquedo principal representativo da brincadeira. Tais brinquedos são geralmente usados por crianças com menor habilidade ou posse. São encontrados brinquedosponte principalmente em brincadeiras que demandam materiais industrializados ou pré-beneficiados.

O instrumento mediador da brincadeira é então alterado utilizando-se geralmente materiais alternativos. Em Belém, para o papagaio (papagaio propriamente dito), o cangula e a rabiola $^{2}$ - que são construídos com materiais industrializados ou pré-beneficiados como o papel de seda, a linha e a tala - existem a pipa ${ }^{3}$ e a curica ${ }^{4}$ como brinquedos-ponte; para o seu fabrico precisa-se somente de papel de jornal, saco plástico e talas de paneiro (bastante abundantes na região); em Campinas verifica-se fenômeno semelhante sendo que o brinquedo-ponte para o papagaio denomina-se de capucheta e é feito basicamente de jornal.

A peteca, que em Belém é "tradicionalmente" praticada com bolinhas de vidro ou bolas de aço de rolamentos, no entanto pode ser brincada com pedras, tampas de refrigerante, caroços de tucumã ${ }^{5}$. O time de botão pode ser brincado com tampas de recipiente de plástico. Faz-se pião com tampa de pasta de dente etc.

2 O Papagaio, a rabiola e o Cangula são feitos com papel de seda e talas de Miriti (Buriti) é obtida com freqüência de vendedores que fabricam em série. São utilizados por sujeitos de faixa etária de 9 à 20 anos. A diferença entre estes tipos deve-se basicamente a quantidade de talas utilizadas ao formato e tipo específico de cruzamento destas talas. A rabiola e o papagaio são feitos de duas talas horizontais e uma tala vertical, na rabiola as duas talas horizontais são menores que a tal vertical, enquanto que no papagaio estas são maiores; o papagaio demanda mais habilidade do empinador. O cangula possui somente duas talas, a horizontal é maior do que a vertical.

3 A Pipa foi o tipo mais comum no ambiente observado. Feito com tala de paneiro (cesto de talas finas e trançado aberto, usado no Pará), as duas talas possuem tamanho igual ou a vertical é maior que a horizontal. As talas são cruzadas no meio da tala vertical. O rabo possui escamas de papel ou de plástico. Geralmente é produzida pelo próprio usuário. È usado por crianças na faixa etária de 7 à 13 anos.

4 A curica é feita geralmente de papel de caderno, pode ter tala ou não; caso tenha tala, esta é de paneiro, por ser mais fina, e é enfiada na horizontal e vertical perfurando o papel, sua principal função é armar o papel, quando a curica fica muito mole. Uma folha de caderno é dobrada ao meio e recortada com a mão, de tal maneira que o miolo da folha fica sendo o corpo da curica e a tira de papel retirada das bordas, o rabo. É empinada por crianças com idade entre 2 e 5 anos, com poucos metros de linha. Geralmente é produzida pelas próprias crianças.

5 Palmeira (Astrocaryum tucuma), que vai a $15 \mathrm{~m}$ de altura e possui espinhos longos e finos. A semente tem formato oval e possui em média $3 \mathrm{~cm}$ de diâmetro.
De forma análoga, encontramos fenômeno semelhante nos brinquedos de faz-de-conta: faz-se móveis de boneca com caixas de palitos de fósforo, constroi-se carros com latas de leite ou de óleo, brinca-se de levar uma boneca para passear apenas com uma tábua (Bichara, 1999). A diferença a nosso ver reside no fato de o brinquedo-ponte ser institucionalmente estabelecido; ele não é um substituto, é o brinquedo do brinquedo. Por outro lado, um brinquedo-ponte, diferentemente de um brinquedo de faz de conta, não se remete ao mundo adulto, seu referencial está na própria brincadeira do mundo infantil.

Acredita-se que todas estas formas alternativas de brincar de determinada brincadeira contribuem para que determinados grupos, quer por pouca posse ou por menor habilidade, pratiquem e/ou sejam introduzidos em determinada cultura do brincar infantil, permitindo assim, que a brincadeira se mantenha à revelia das condições econômicas ou das habilidades que ainda não foram desenvolvidas. Brinquedos-ponte fazem a ponte com o brinquedo principal, introduzem ou mantêm uma prática alternativa, institucionalmente estabelecida, de um brinquedo culturalmente desenvolvido no mundo infantil.

\section{Os brinquedos aparentados: criando o clima}

Se nos brinquedos-ponte existe uma réplica do brinquedo principal, nos brinquedos aparentados o brinquedo utilizado é de natureza diferente, mas alguma característica do brinquedo principal é preservada.

Sabe-se que algumas brincadeiras apresentam-se sazonalmente. Os brinquedos aparentados são brinquedos que acompanham a brincadeira principal da época, são geralmente atrelados a ele, fazem parte do clima criado por uma brincadeira, da atmosfera que envolve as crianças de modo a partilharem as brincadeiras. Como os brinquedos aparentados partilham alguma característica entre si, algumas habilidades são então também compartilhadas ou fazem parte de um tema central.

Do mesmo modo que determinado período festivo é configurado de vários eventos ou elementos que caracterizam este período o mesmo parece ocorrer em algumas "épocas" ou "tempo" de determinadas brincadeiras. Na época de "São João", vários componentes culturais (culinária, dança, música, vestuário) fazem parte do que caracteriza o período, o mingau, o aluar (bebida típica da região norte), bolo de fubá, o forró, quadrilha, a roupa típica etc.

Em Belém, algumas brincadeiras estão associadas à época do papagaio. São estas a "puira", o "bode" e a "pena".

6 Dois sujeitos trançam um pedaço de linha encerada(com cortante) de aproximadamente $30 \mathrm{~cm}$ e fazem movimentos de "vai-vem". Ganha quem conseguir cortar a primeiro a linha do contendor.

7 Amarra-se uma linha encerada em uma pedra (Bode propriamente dito) joga-se em direção ao bode do adversário, dando-se puxões repentinos na linha com o objetivo de cortar o bode adversário.

8 Com uma linha de aproximadamente $50 \mathrm{~cm}$ e amarra-se em uma das pontas do papel bombom. A outra ponta da linha enrola-se em uma pedra pequena, de aproximadamente $3 \mathrm{~cm}^{2}$ de modo que a ponta do 
Cada um destes brinquedos parentes partilha alguma característica em comum com o papagaio; pode-se dizer que a puira e o bode são uma ritualização do laço ${ }^{9}$, e a pena é uma ritualização do pegar o papagaio que china ${ }^{10}$. Acredita-se que estas brincadeiras, além de contribuírem para criar uma atmosfera que envolve a comunidade, possibilitam o treino de alguma das habilidades principais envolvidas no brinquedo principal.

Curiosamente estas brincadeiras são peculiarmente desenvolvidas nos fins de tarde, momento em que os empinadores começam a recolher seus papagaios. Apesar de medidas mais precisas serem necessárias, sabe-se assistemáticamente que as verbalizações caracterizam-se por relatos de façanhas e deboches de conteúdo referente a acontecimentos do dia no papagaio, tal como professores universitários que saem do trabalho e vão ao bar comentar coisas do trabalho. Estas brincadeiras são somente o pano de fundo destas interações sociais, interações que transmitem cultura.

\section{As formas brandas: o brincar de brincar}

Bussab (1986) define o brincar como uma forma de experimentar em uma situação protegida. No entanto o brincar à revelia desta definição sempre envolve risco, o risco da perda, o risco da chacota, o risco das sanções. São exatamente estes riscos que parecem dar a tensão necessária de uma competição. Para se evitar o risco deve-se desenvolver habilidades necessárias para ser um bom competidor. No entanto, a oportunidade de desenvolver a habilidade se dá dentro da brincadeira, ou seja dentro da situação que envolve risco.

Este dilema tende a produzir uma configuração de grupo que se caracterizará pela organização em função do grau de habilidade ou de competência no jogo, ou seja, que inábeis procuram inábeis e evitam os hábeis e vice-versa. Seja em que sentido for, a segregação é sempre ativa.

Como habilidade advém basicamente de experiência, e experiência correlaciona-se positivamente com idade, as crianças tendem a se agrupar em faixas etárias um tanto estreitas. Nesta forma de agrupar, o círculo de conhecimentos culturalmente construídos tende a se organizar em estratos: as experiências são oportunizadas dentro de estratos específicos. É claro que, no caso específico aqui discutido, determinados indivíduos transitam entre estratos inferiores e superiores possibilitando a transmissão da cultura, como uma corrente onde uma ponta é ligada à outra através de várias argolas.

No entanto, outras formas de se organizar são possíveis, e estas formas podem já estar codificadas na própria brincadeira. Em alguns casos é possível que crianças com níveis de habilidades bastante díspares partilhem as brincadeiras,

papel encoste na pedra. Em seguida joga-se a pedra com bastante força no ar. O papel e a linha se soltam e o objetivo é pegar a "pena" por primeiro.

9 Trançar de papagaios no ar para fins de cortar a linha do oponente.

10 Papagaio que cai no ar depois de um laço. bastando para isso que a brincadeira seja adaptada à criança com menos habilidade; denomina-se estas formas adaptadas de brincadeira de "formas brandas".

As formas brandas das brincadeiras caracterizam-se por serem adaptações nas brincadeiras de modo a serem dispensadas dos participantes algumas habilidades mais complexas elou abrandadas ou suspensas as penas; geralmente tais formas são denominadas "café com leite" ou "neném". Em várias brincadeiras, tanto de meninos, como de meninas, um acordo inicial entre os participantes determina o grau de habilidade que será exigido para prática. Esse é o caso de algumas brincadeiras registradas em Belém como a corda, $o$ elástico, a macaca ${ }^{11}$, o fura-fura ${ }^{12}$ etc.

Tais formas de brincar propiciam experiências e facilitam a penetração de crianças com habilidades menos desenvolvidas nas formas mais avançadas, possibilitando assim uma transmissão da cultura de um modo menos estratificado.

Se o brincar já é uma forma de experimentar em uma situação protegida, o brincar com formas brandas torna a situação mais protegida ainda, como se fosse o brincar-debrincar, o brincar com menos riscos.

Contudo, apesar de tal forma de brincar estar verbalmente codificada, ela não determina linearmente a maneira como o grupo irá se organizar, ou seja como a rede de relações de um determinado grupo estará estruturada naquela brincadeira; sua codificação possibilita determinada organização mas não a determina exclusivamente. É a relação entre os membros do grupo que em última instância determinará o acolhimento de determinado sujeito menos experiente, e o grau de tolerância e aceitação sempre variará de díade para díade.

No elástico, uma brincadeira predominantemente feminina, existe uma forma do participante brincar que é menos rigorosa e permite a opção de entrar em qualquer fase da brincadeira; denomina-se a criança que participa da brincadeira deste modo de "anjinho". O anjinho não é obrigado a jogar todas as seqüências e mesmo que erre não sai do jogo; ele entretanto não opta pelas fases, deve apenas imitar o participante. São anjinhos geralmente as crianças aprendizes ou crianças que chegam ao grupo depois da brincadeira ter iniciado. Ressalta-se que um anjinho só entra na brincadeira com a anuência de algum dos participantes maiores. A verbalização abaixo é um extrato de uma observação deste jogo em que tal permissão é pedida.

Situação: Meninas brincando de elástico (sujeito Lai - 10 anos, sujeito Mar - 10 anos, sujeito Van - 14 anos). Sujeito Cel - 11 anos se aproxima e pede para entrar na brincadeira.

Sujeito Cel: Pede para entrar na brincadeira como anjinho. "Posso ser anjinho"

Sujeito Mar: "Pode"

11 Mais conhecida como amarelinha.

12 Arame grosso com uma das extremidades pontiagudas e a outra enfiado geralmente em um pedaço de $10 \mathrm{~cm}$ de um cabo de vassoura. Utilizado para fincar na terra e brincado em diferentes modalidades. 
Sujeito Lai: "Comigo não"

Sujeito Van: "Eu não quero anjinho no meu, demora muito e atrapalha".

O vencedor desta partida foi o sujeito "Mar", o único que aceitou o anjinho; ao final da partida constatou-se que os sujeitos "Cel" e "Mar" são primas.

Cada característica estrutural verbalmente codificada existe independente das relações e impõe-se a estas, é um dos seus determinantes. Contudo, a estrutura de uma brincadeira não determina totalmente as interações entre os sujeitos de modo a eliminar as características peculiares de suas relações; a estrutura interage com as relações anteriormente dadas. As interações nas brincadeiras serão fruto do institucionalmente dado e das relações entre seus membros.

\section{Referências}

Aurélio, B.H.F. (2000). Novo Aurélio: o dicionário eletrônico da língua portuguesa, século XXI - versão 3.0. Rio de Janeiro: Lexicon informática / Nova fronteira.

Avedon, E. (1971). The strutural elements of games. In Avedon, E. e Sutton-Smith, B. (Eds.). The study of games. New York: John Wiley \& Sons.

Avedon, E. \& Sutton-Smith, B. (1971). The study of games. New York: John Wiley \& Sons.

Bussab, V.S.R. (1986). Material não publicado.

Bichara, I.D. (1999). Brincadeira e cultura: o faz-de-conta das crianças Xoco e do mocambo (porto da folha/se). Material não publicado.

Bomtempo, E., Hussein, C.L. \& Zamberlan, M.A.T. (1986). Psicologia do brinquedo: aspectos teóricos e metodológicos. São Paulo: Nova Stella - Editora da Universidade de São Paulo.

Friedmann, A. (1990). Jogos Tradicionais na cidade de São Paulo: Recuperação e análise de sua função educacional. Dissertação de Mestrado, Universidade Estadual de Campinas, Campinas.

Friedmann, A. (1996). Brincar: Crescer e Aprender: o Resgate do Jogo. São Paulo: Moderna.

Kishimoto, T.M. (1993). Jogos tradicionais infantis: o jogo, a criança e a educação. Petrópolis: Vozes.

Medeiros, E.B.M. (1990). Brincadeiras e brinquedos como manifestação cultural. Cadernos do EDM: Comunicações \& Debates, 2, 132-140.

Neto, S.J. (1977). O jogo de bolinhas de gude. Cadernos do folclore. MEC.

Opie, I. e Opie, P. (1976). Street games: coounting-out and chasing. Em Bruner, Jerome S.; Jolly, Alison \& Sylva, Kathy(Org), Play-its role in development and evolution (pp. 395-412). New York: Peguin.

Parker, S.T. (1984). Playing for keeps: An evolutionary perspective on human games. Em P.K. Smith (Org.). Play in animals and humans (pp. 271-293). Oxford, UK: Basil Blackwell.

Piaget, J. (1977). O julgamento moral da criança. (E. Lenardon, Trad.). São Paulo: Mestre Jou, (Trabalho original publicado em 1932).
Pontes, F.A.R. (1986). Levantamento por observação das atividades exercidas pelas crianças em ambiente externo e escolar com vista a subsidiar a elaboração do currículo e das atividades de uma pré-escola comunitária. Trabalho de conclusão de curso de bacharelado em Psicologia; Universidade Federal do Pará.

Pontes, F.A.R., Galvão, O.F. (1992). Estudo descritivo das regras do jogo de peteca (bola de gude). Boletim de Psicologia, Sociedade de Psicologia de São Paulo, 42 (96/97), 79-88.

Pontes, F.A.R., Galvão, O.F. (1997). Desenvolvimento do seguimento de regras no jogo de peteca (bola de gude). Psicologia: Teoria e Pesquisa, 42, n.2, 79-88.

Redl, F., Gump, P. \& Sutton-Smith, B. (1971). The dimensions of the games. Em Avedon, E. \& Sutton-Smith, B. (Org.). The study of games. New York: John Wiley \& Sons.

Souza, A.R. (1999). Brincadeiras populares e suas contribuições para o desenvolvimento infantil. Material não publicado.

Souza, A.R. (1999b). Resolução de conflitos entre crianças em brincadeiras de rua. Dissertação de Mestrado apresentada à pós graduação em psicologia: Teoria e Pesquisa do comportamento. Universidade Federal do Pará.

Tavares, R.M.M. (1994). Brinquedos e brincadeiras: patrimônio cultural da humanidade. Coleção memorial, Vol. 1. Campinas -SP. 